\title{
Psychosexual development and quality of life outcomes in females with congenital adrenal hyperplasia
}

\author{
Mansi Kanhere ${ }^{1}$, John Fuqua ${ }^{2}$, Richard Rink ${ }^{3}$, Christopher Houk ${ }^{4}$, David Mauger ${ }^{5}$ and Peter A. Lee ${ }^{6 *}$
}

\begin{abstract}
Background/Aims: Outcome information regarding females with classical congenital adrenal hyperplasia (CAH) have generally suggested poor quality of life (QoL), general maladjustment, problems regarding sexuality, and decreased fertility. The aim of this study was to assess QoL, psychosocial adaptation, and psychosexual characteristics, includingchildhood gender role behavior, gender identity, and sexual orientation in females with CAH.

Methods: Female patients with 21-hydroxylase deficiency CAH were evaluated using a questionnaire with items relating to knowledge of their condition and its therapy; consistency of medical, surgical, and psychological care; childhood friends and play behavior; and genital, pubertal, and sexual development. The subjects' perception of outcome was compared with family support and adolescent and adult QoL perspectives, including social relationships, self and body image, and gender and sexual issues.
\end{abstract}

Results: Childhood play and gender characteristics, childhood and adult genital perception, and sexual identity and orientation varied as previously reported. However, most patients indicated good family support, understanding of their condition, good quality medical care, positive self-satisfaction, indices of happiness and body image perception, and satisfaction with their sex lives.

Conclusion: The data reported here suggest that overall outcome can be very good for females with $\mathrm{CAH}$ and that good outcome appears to relate to quality of care and positive social support.

The psychosocial outcomes of female patients with congenital adrenal hyperplasia $(\mathrm{CAH})$ have not been consistently defined. Outcome information is limited regarding females who have the classical form of $\mathrm{CAH}$, with reports of poor quality of life (QoL), general maladjustment, problems regarding sexuality, and decreased fertility [1, 2]. Among some, previous genital surgery was probably less refined than currently and may have resulted in external genitalia that impaired both sexual intercourse and sexual responsiveness. With refinements in medical therapy and surgery and changes in societal perspectives regarding gender and sexuality, QoL factors, including socialization and sexuality, need further assessment. Recent studies on QoL and psychosocial adjustment suggest less than satisfactory results; women with

\footnotetext{
* Correspondence: plee@psu.edu

${ }^{6}$ Department of Pediatrics, Penn State College of Medicine, 500 University Drive, Hershey, PA 17033-0850, USA

Full list of author information is available at the end of the article
}

CAH have anxiety related to the appearance of their genitalia and decreased body image satisfaction leading to avoidance of sexual activity [3-5].

Exposure of the developing brain to androgens during fetal life is understood to impact post-natal gender and sexual development, including sexual orientation, although these relationships are both multifactorial and not predictable. Gender identity studies from 1950 to 2004 found that while females with $\mathrm{CAH}$ are more likely to exhibit male-typical childhood play, the majority who are raised female identify as female and live in their assigned gender [6]. Nevertheless, women with $\mathrm{CAH}$ have increased rates of non-heterosexual orientation as compared to the general population. The true frequency is unclear, since reported frequencies range from 3-31\% [7].

The impact upon QoL of factors such as family support, consistent medical care, and psychological counseling remain unverified. The hypothesis of this study 
was that family and other social and psychological support result in more positive perspectives during childhood and are related to factors suggesting better QoL during young adult life. To address these issues, herein we report results from a questionnaire for adult and adolescent females with $\mathrm{CAH}$ together with review of available medical and surgical history.

\section{Patients and methods}

\section{Study population}

Eighty-nine adolescents and adult women aged $\geq 14$ were mailed questionnaires using the latest available address. Of these, 25 were undeliverable; of the 64 that were not returned, 37 did not respond, 27 responded with completed surveys. Data were coded by number, and only assessed as group data. Subjects were current or former patients treated by the Pediatric Endocrinology or Pediatric Urology Divisions at Riley Hospital for Children or former patients of an author (PAL) from the Children's Hospital of Pittsburgh. Most were identified from medical records at Riley Hospital or the investigators' research records, and a questionnaire was sent by mail. Research data were collected from the questionnaire. All had classic CAH (21-hydroxylase deficiency). Patients with additional diagnoses or chronic diseases were excluded.

Institutional review board approval was obtained at the Indiana University School of Medicine. Completion of the questionnaire was considered to be consent to participate.

\section{Methods}

The specific aim of this study was comparison of responses to a questionnaire that was derived from general questionnaires in the public domain (Table 1), with items relating to patients' knowledge of their condition and therapy; consistency of medical, surgical, and psychological care; childhood friends and play behavior; and genital, pubertal, and sexual development, perceptions, and experience. The participants indicated their age in years on the questionnaire as one of 4 groups: age 14 to 17,18 to 21,22 to 25 , and $\geq 26$. Their specific age was not available to us according to the IRB approval that considered the completion of the questionnaire as consent. Participants were allowed to omit answers to questions if they chose not to respond. Comparisons were made between the quality of surgical and medical therapy and family support vs. adolescent and adult QoL perspectives including social relationships, self and body image, and gender and sexual issues. The questionnaire consisted of 50 questionsl including closed-ended questions with a yes/no answer, nominal questions with graded responses from most favorable to least favorable, and open ended questions to allow subjects to express
Table 1 Source references for questionnaire

\begin{tabular}{l} 
1. Body Esteem Scale:S.L. Franzoi, S.A. Shields, (1984. Journal of \\
Personality Assessment 1984; 48, 173-178. \\
2. Female Sexual Function Index (FSFI) R. Rosen, C Brown, Heiman J, \\
Leiblum S, Meston C, Shabsigh R, Ferguson D, D'Agostino R Jr. \\
J Sex Marital Ther. 2000;26(2):191-208 \\
3. National Health and Social Life Survey (NHSLS Laumann EO, Gagnon JH, \\
Michael RT, Michaels S. Chicago: University of Chicago Press, 1994. \\
4. Recalled Childhood Gender Identity Scale HF Meyer-Bahlburg, \\
C Dolezal, K Zucker, SJKessler, JM Schober, MI New. J Sex Res. \\
2006;43:364-367 \\
5. Sexual Behavior Assessment Schedule-Adult ((SBAS-A) de Souza Pinto D, \\
CLV Filho, Wainberg ML, de Mattos PEL, Meyer-Bahlburg HFL, Rev. \\
psiquiatr. Rio Gd. Sul vol.29 o.2 Porto Alegre 2007 http://dx.doi.org/ \\
10.1590/S0101-81082007000200012 \\
6. SF-36 (www.Sf-36-org) \\
7. The Gender Identity/Gender Dysphoria Questionnaire for Adolescents \\
and Adults JJ Deogracias, LL Johnson, Meyer-Bahlburg HF, Kessler SJ, \\
Schober JM, Zucker KJ. Sex Res. 2007; 44:370-379. doi:10.1080/ \\
00224490701586730. \\
8. The Masculine Gender Identity Scale for Females Blanchard R, Freund K, \\
Journal of Consulting and Clinical Psychology,1983; 51: 205-214. \\
http://dx.doi.org/10.1037/0022-006X.51.2.205 \\
9. The Sex Role Behavior Scale-Orlofsky JL1, O'Heron CA. Orrlafsky and \\
O'Heron J Pers Assess. 1987; 51:267-77. \\
\hline
\end{tabular}

personal opinion. The questionnaire is avaliable as Additional file 1.

The initial goal of the protocol was to compare severity of virilization at birth, genital surgery, and indices of glucocorticoid suppression with outcome indices. However, for the majority of study subjects adequate medical and surgical information was unavailable. Hence, statistical consultation (DM) recommended that responses be grouped to answer hypothesis-driven questions. These were as follows: to determine whether there was a direct relationship(s) between a) positive family support and positive self-esteem, b) recalled childhood and adult genital perceptions, c) understanding their condition, long-term physician relationship, and compliance, d) childhood gender view and behavior (male-type) and adult perceptions (wanting to be a man, preferred sexual partner), e) level of education, perceived knowledge of condition, family support, medication adherence, and adult social and sexual relationships and f) adult self perception, social relationships and sexual activities.

\section{Statistical analysis}

Statistical analysis included descriptive statistics (mean, standard deviation, median and range of scores for each question). Fisher's Exact Test was used to compare outcome variables related to socialization, gender, and sexuality. 


\section{Results}

\section{Demographics and diagnosis understanding}

Table 2 outlines the demographic characteristics of the subjects, including age category at the time of the study, living conditions, perception of family income, level of education, and understanding of diagnosis. Based upon available records, 17/27 (63\%) of the total subjects were considered to be salt-losers. Based upon the limited information available, the majority were assumed to have mildly to moderately virilized genitalia. As outlined in Table 2, the majority of the women thought they knew enough about their diagnosis to care well for themselves, and only $1 / 27$ (3\%) felt she understood the disease poorly.

\section{Family support}

Eighty-two percent of women felt their families had been very supportive. All 9 who thought that one family member was more supportive indicated their mother, with 3 including their siblings and 1 including her father. Four of the 26 women (15\%) thought one family member was less supportive, 1 naming her mother and the other their father, siblings, and both. The attitudes of the non-supportive member regarding their condition was described by 2 subjects as embarrassment and shame, while one reported an acceptance of her condition. Twelve of 27 (44\%) women had a sibling or siblings with $\mathrm{CAH} ; 4$ were male, 5 female, and 3 with both. Seven of these (58\%) thought having a sibling helped in their care; including 4 who had a male sibling and 3 who had siblings of both sexes. Of the $5(42 \%)$ who felt having a sibling did not make a difference, 4 had female siblings and 1 had a male sibling.

\section{Duration of care by endocrinologists, compliance, and medication side effects}

Table 3 depicts duration of care by endocrinologists. One person noted she had not had any care since loss of her parents' insurance coverage at age 23 years. Frequency of compliance with medications is also shown in Table 3. Compliance was poorest during adolescence. Twenty-three of 24 (96\%) were responsible for taking their own medications. 16/23 (70 \%) reported treatment compliance was the same since taking responsibility, 3 of $22(13 \%)$ said it was better and 3/22 (13\%) said it was worse. Figure 1 depicts side effects of medications. Other less frequently reported side effects were poor bone strength, stretch marks, and acne.

\section{Self-satisfaction}

Figure 2 shows the percentage of women who strongly agreed/agreed with having positive attitudes, being selfsatisfied, self-competent regarding their abilities, and with having feelings of self-worth.

\section{Body image perception}

Selected body image perceptions were: 19/23 (83 \%) wanting to be taller, and 18 (78 \%) wanting to weigh less. Eight women (35\%) wanted larger breasts, 6 (26\%) wanted different genital appearances, $4(17 \%)$ thought they had too much facial hair, and $4(17 \%)$ thought they had too much body hair.

\section{Physical pubertal development}

Figure 3 depicts age of onset of pubertal milestones. The age at thelarche and pubarche was late for most,

Table 2 Demographic characteristics, understanding of diagnosis and family support

\begin{tabular}{|c|c|c|c|c|}
\hline Age group, y & $14-17$ & $18-21$ & $22-25$ & $>26$ \\
\hline$n=27$ & 7 & 6 & 5 & 9 \\
\hline Living conditions, no. (\%) & Overcrowded urban area & Rural area & Many close neighbors & \\
\hline$n=27$ & $1(4)$ & $6(22)$ & $20(74)$ & \\
\hline Perception of family income, no. (\%) & Less than average & Comparable & Higher than average & \\
\hline$n=24$ & $3(11)$ & $15(56)$ & $6(22)$ & \\
\hline Level of education, no. (\%) & Less than High School & Graduated High School & Some College & $\begin{array}{l}\text { Completed College } \\
\text { and beyond }\end{array}$ \\
\hline$n=27$ & $6(22)$ & $9(33)$ & $5(18)$ & $7(25)$ \\
\hline Understanding of diagnosis, no. (\%) & Very well & Fairly well & Adequate & Poorly \\
\hline$n=27$ & $7(25)$ & $9(33)$ & $10(37)$ & $1(3)$ \\
\hline $\begin{array}{l}\text { Person who helped with } \\
\text { understanding diagnosis, no. (\%) }\end{array}$ & Parents & Medical Doctor & $\begin{array}{l}\text { Both parents and } \\
\text { Medical doctor }\end{array}$ & $\begin{array}{l}\text { Parents, Medical Doctor } \\
\text { and Surgeon }\end{array}$ \\
\hline$n=23$ & $1(4)$ & $1(4)$ & $15(65)$ & $6(26)$ \\
\hline Family support & Very supportive & Uncomfortable discussing it & Avoid discussing it & Not supportive \\
\hline$n=23$ & $19(82)$ & $2(9)$ & $1(4)$ & $1(4)$ \\
\hline
\end{tabular}


Table 3 Duration of care by endocrinologist and compliance with medications

\begin{tabular}{llll}
\hline Duration of care by endocrinologist, no. (\%) & Long as I remember & At least 10 years & Between $5-10$ years \\
$n=24$ & $15(62)$ & $2(25)$ & $3(12)$ \\
Compliance with medications, no. (\%) & Most of the time & Usually compliant & Never \\
$n=27$ & $23(92)$ & $3(11)$ & $1(4)$ \\
Age of most non-compliance, no. (\%) & Childhood & Adolescence & Never missed medication \\
$n=22$ & $6(26)$ & $12(56)$ & $4(17)$ \\
\hline
\end{tabular}

reported between 11 and 14 years for $70 \%$; two women (10\%) indicated it had not yet occurred. Thirteen of 22 (59\%) had attained menarche between 9 and 13 years of age, and 6 reached menarche between ages 14 and 17 years. All except $3(19 / 22,86 \%)$ reported having regular menstrual cycles.

\section{Childhood play and gender characteristics}

Figure 4 depicts childhood play preferences and adult sexual orientation. Of 23 subjects who answered the question, 3 (13\%) preferred female playmates, 14 (60\%) were neutral, and 7 (30 \%) preferred male playmates; data suggest these results were confounded by gender of siblings. Subjects were asked to select all applicable play preferences. Male-type play preferences were defined as toy cars/planes, sports, and rough and tumble play, and female-type play was defined as dolls/play houses and dressing up. Similarly, recalled childhood fantasy roles are shown in Fig. 4. The relationship between childhood fantasy roles and gender identity as an adult was statistically significant $(p=0.003)$. Those who assumed only female roles never experienced a desire to be a man. Of the 9 who assumed mostly female roles, 8 reported never wanting to be a man, with one $(11 \%)$ reported feeling this occasionally. Among the 5 girls who reported gender neutral fantasy roles, 2 indicated that they never wanted to be a man whereas 3 reported that this occurred occasionally. The one subject who preferred masculine fantasy roles as a child reported an occasional desire to be a man.

\section{Self-image, physique perception and happiness index}

Figure 5 depicts the femininity, self-image, and physique perception as a child, in later stages of adolescence, and as an adult. These were reported as graded responses on a scale of $1-5$, with 1 as best and 5 as worst. The percentages of women who picked each response are depicted in the figure. Compared to other girls during their childhood, only 2 of 27 (7\%) women felt more feminine, 8 (30\%) were about the same, and 17 (63\%) felt less feminine. Regarding a happiness index ("being happy about the kind of person you are") as an adolescent, among 27 responders 21 (77\%) reported generally being happy, 2 (8\%) being indifferent, and 4 (15\%) being mostly unhappy. Self-image as an adolescent was reported by 10 of 23 (43\%) as positive and 10 of 23 (43\%) as ambivalent, with negative responses by 3 (13\%). Perception of physique in 26 patients was moderate to strongly positive for 14 (54 \%), indifferent for 1 (3.8\%), and moderate to strongly negative feelings for 11 (42\%).

SIDE EFFECTS OF MEDICATIONS

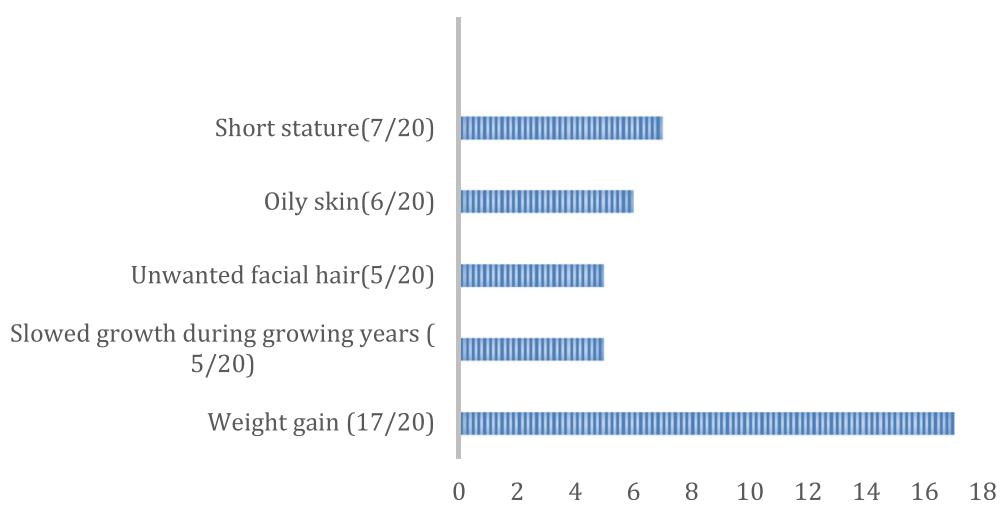

Fig. 1 Side effects of medications as reported by the subjects 


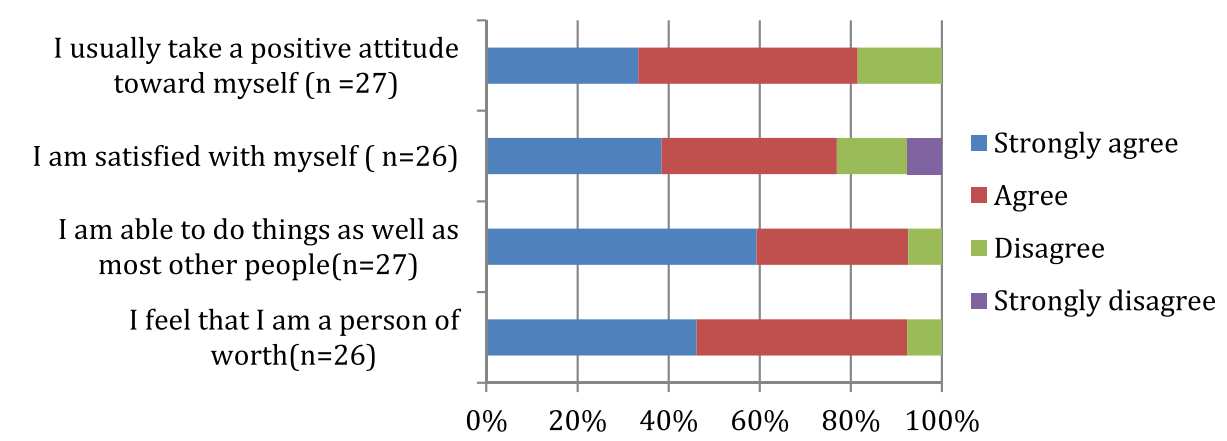

Fig. 2 Questionnaire results: self worth and self satisfaction

Among those who had a positive physique perception, $82 \%(9 / 11)$ report having had intercourse with a male; the other 2 had not. However, among those who reported a negative perception, 7 of 10 had had intercourse with a male and 3 had not had not $(p=0.004)$.

\section{Genital perception as a child versus as an adult}

Among 20 patients, genital perceptions during childhood were perceived as like those of other girls for 11 (55\%), as different but acceptable for 5 (25\%), and as unacceptable for 4 (20\%). Current genital self-image among 23 patients was positive in 12 (52\%), acceptable for 7 (30 \%) who indicated that they wished they looked better, and $4(17 \%)$ were unhappy with their genital appearance.

Comparing childhood and adult perceptions, 9 of 11 $(81 \%)$ women who thought their genitals appeared similar to those of other girls in childhood were happy with their appearance in adulthood; the remaining $18 \%(2 / 11)$ wished they looked different. Of the 9 women who thought their genitals were different in childhood, only 1 (11\%) was happy with the appearance in adulthood and 8 (89 \%) were unhappy with their appearance and wished they looked better $(p=0.002)$.

\section{Social and sexual relationships}

The majority of women ( 21 of $24,87.5 \%$ ) thought their condition did not interfere with social relationships, while 3 of 24 (12.5\%) indicated that it did. All 3 attributed this to "feeling different" and one to lack of confidence and the way people responded to her. A smaller majority (13 of 22, $59 \%$ ) felt that their condition did not interfere with their sexual relationships, with the remaining 9 (41\%) indicating that it did. These 9 attributed it to "feeling different" and "being embarrassed about their body". One woman indicated it was because she was homosexual and afraid to reveal this and another because she only recently started to use dilators.

When comparing self-image relative to peers with feelings of loneliness, 3 of 7 of those who saw themselves as

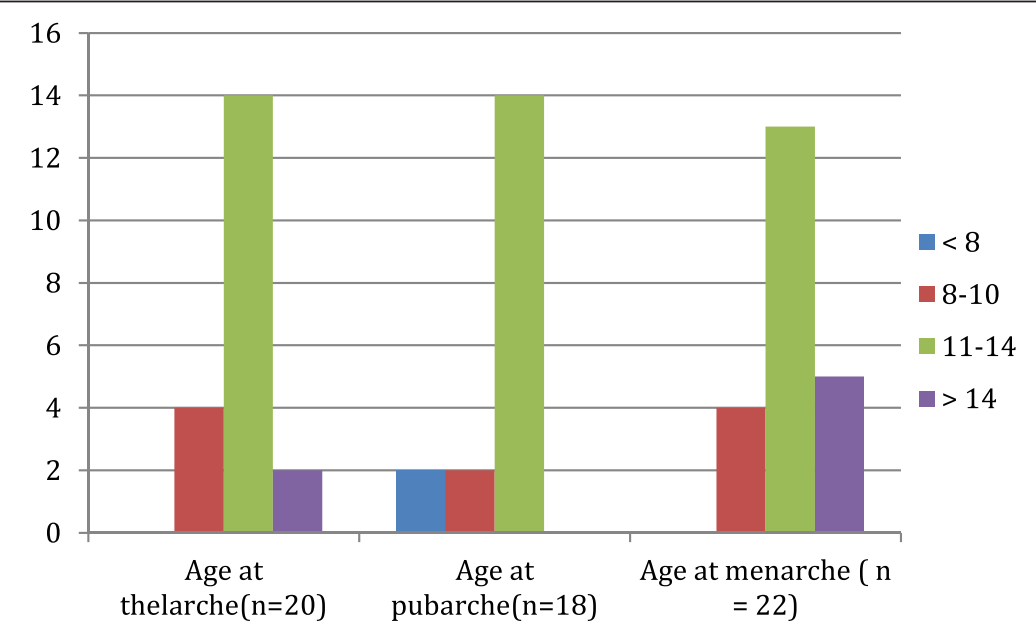

Fig. 3 Age of onset of pubertal milestones 


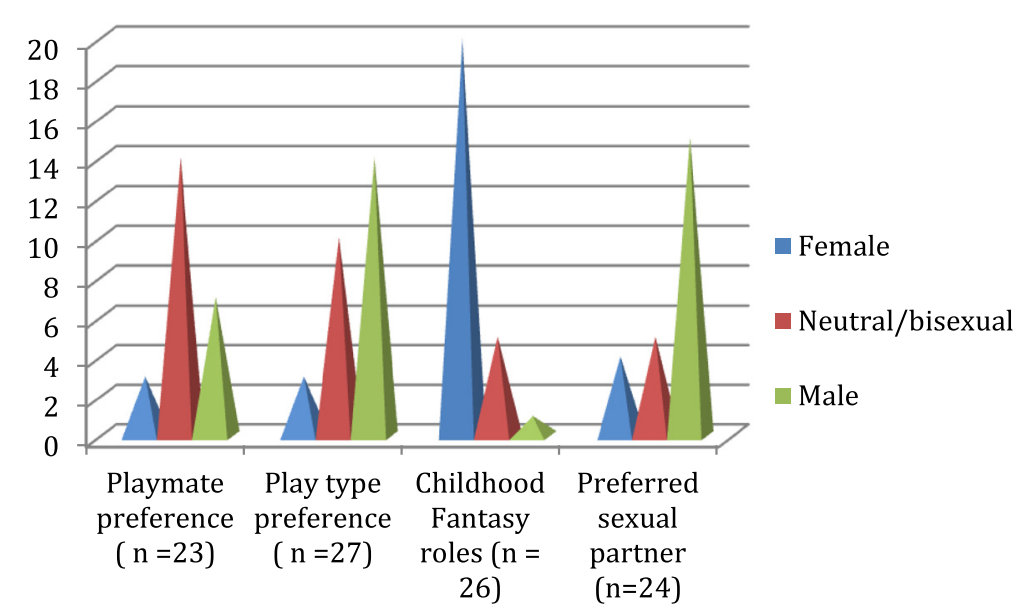

Fig. 4 Declared adult sexual orientation identified as toward females, neutral/bisexual, or male compared with recalled childhood play preferences

not different at all from peers reported no feelings of loneliness, and 4 reported feeling lonely occasionally. Among those who saw themselves as a little different, $7 \%(1 / 14)$ reported no loneliness, $57 \%$ (8/14) reported feeling lonely a few times in the last month, $7 \%(1 / 14)$ felt lonely half the time, and $28 \%$ (4/14) felt lonely most of the time in the last month. For the women who saw themselves as very different from their peers, 1 of 3 reported feeling lonely half the time and 2 of 3 most of the time $(p=0.06)$.

\section{Sexual identity and orientation}

Sexual identity reported as frequency of desire to be a man, sexual orientation, and age of first intercourse are shown in Table 4. Seventeen of 25 (68 \%) had achieved one or more of the sexual development milestones with males, including oral sex and/or sexual intercourse, 2 had never had intercourse but had been involved with kissing, and $6(24 \%)$ reported none. Thirteen of 22 (59 \%) reported no physical involvement with females, 8/22 (36 \%) women had some involvement including kissing, fondling, petting and oral sex, and 3/22 (14\%) had had genital to genital contact.

The relationship between childhood fantasy roles and gender of preferred sexual partner was statistically significant $(p=0.02)$. Seven of 8 women $(87 \%)$ who reported having only female fantasy roles preferred only male partners, while the other one preferred mostly male

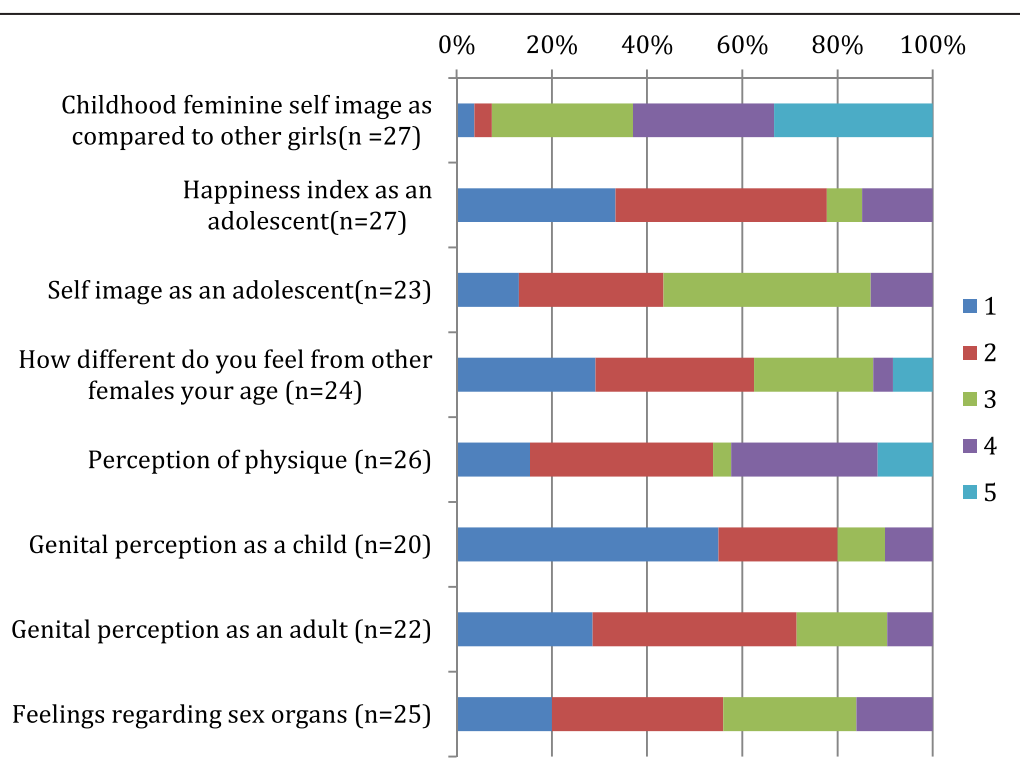

Fig. 5 Self-image, physique and genital perception (Graded responses with best outcome =1; worst outcome = 5). The percentage of women who picked each response is depicted in the figure 
Table 4 Sexual identity and orientation

\begin{tabular}{llll}
\hline Desire to be a man, no. (\%) & Never & Occasionally & Always \\
$n=24$ & $18(75)$ & $6(25)$ & 0 \\
Preferred sexual partner, no. (\%) & Only/mostly male & Either males or females & Only/mostly female \\
$n=24$ & $15(62)$ & $5(21)$ & $4(16)$ \\
Age of first intercourse, no. (\%) & $>18$ & $14-17$ & $<14$ \\
$n=15$ & $9(60)$ & $6(40)$ & 0 \\
\hline
\end{tabular}

partners. Among patients indicating mostly female fantasy roles, $40 \%(4 / 10)$ preferred only male sexual partners, $10 \%(1 / 10)$ preferred mostly male partners, $30 \%$ (3/10) were bisexual, and $20 \%(2 / 10)$ preferred only female partners. Of those expressing neutral childhood fantasy roles, $20 \%(1 / 5)$ preferred only male sexual partners, $20 \%(1 / 5)$ preferred mostly male partners, $40 \%$ $(2 / 5)$ were bisexual, and $20 \%(2 / 10)$ preferred mostly female partners. The one who preferred masculine fantasy roles as a child reported preferring only female partners.

\section{Satisfaction with sexual life}

Figure 6 outlines issues related to sexual function: achievement of orgasm with stimulation of the clitoral/ genital area, ability to insert a tampon, and achievement of intercourse with a male. Regarding sensations from stimulating the clitoris, on a scale of $1-5$ with 1 being very good and 5 being poor, $77 \%(14 / 18)$ reported them to be good, $23 \%(4 / 18)$ thought they were adequate, and none reported them as poor. Of the 12 women who reported having sexual intercourse with a male, 6 (50\%) indicated difficulties; 5/12 (42\%) stated that it was painful. Four of the 10 (40\%) women who had never had intercourse with a male felt this was because they preferred females.

\section{Discussion}

This limited report of factors that impact QoL suggests reasonable outcome for $46, \mathrm{XX}$ patients born with moderate virilization due to $\mathrm{CAH}$. The results are consistent with our hypothesis that family and other social and psychological support correlate with positive perspectives during childhood and better QoL during young adult life. These findings are consistent with reported studies relating to QoL. The statistical correlation between assuming a masculine fantasy role in childhood and both the desire to be male and a non-heterosexual orientation supports the theory by Hines et al. that recalled maletypical play in childhood correlates with reduced satisfaction with the female gender and reduced heterosexual interest in adulthood [8]. Previous reports have found poor satisfaction with body appearance, including genital appearance, while this report found a generally positive perception of physique that was statistically associated with having had sexual intercourse with males, consistent with recent reports $[5,9]$. The QoL of most of the patients reported are reasonable compared with previously reported poorer QoL outcomes for adult women with $\mathrm{CAH}$ when compared with controls [10], albeit not associated with atypical gender role behavior [11]. When compared with a reference group, sexual function and

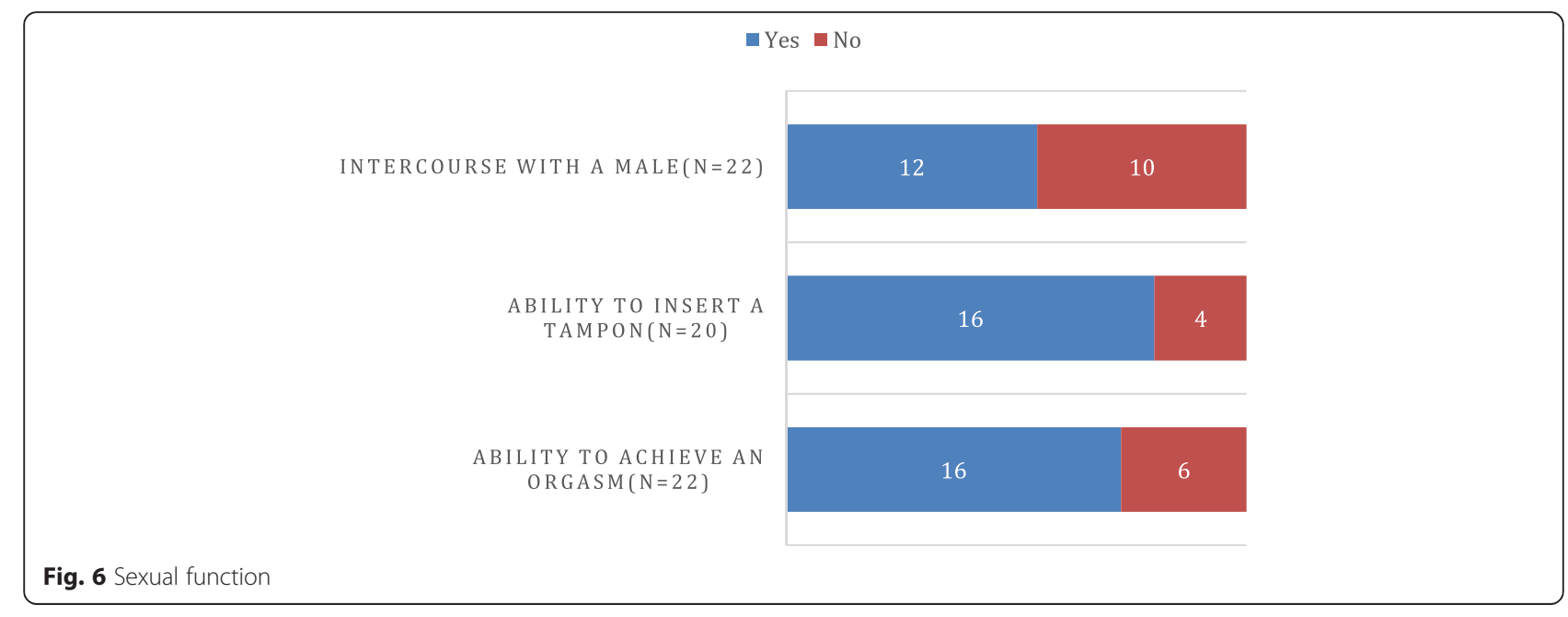


functional outcome is less favorable [12]. Assessment of clitoral sensitivity among 10 sexually active patients with $\mathrm{CAH}$ was found to be significantly reduced compared with controls, but sexual function was not statistically or clinically significantly different. These data are consistent with good healthy sexual function among those in a healthy social situation even with diminished sensitivity [13].

Our findings of $68 \%$ having had oral or genital intercourse or both with a male and $73 \%$ having had an orgasm appears within the range of published reports $[5,12]$. While many of our patients had not had intercourse with a male, this may be related to age and preference for female partners. In prior studies, the frequency of women who have experienced intercourse is generally low. Pain with intercourse was reported in $42 \%$, compared with previous reports ranging from 25 to $81 \%$ $[12,14]$. Although reported perceived sexual functioning was less satisfactory than reference groups [12], more than $80 \%$ reported being able to achieve orgasm.

Most of our patients denied ever wishing to be male, and $60 \%$ indicated sexual preference for males only, a minority having had sexual encounters with another female. Sixteen percent indicated sexual preferences for females, compared with 19 to $20 \%$ of adult women with CAH reported in other studies $[7,14]$. This study and a recent study did not identify any severe gender dysphoria, but incidences of 5 and $10 \%$ have been reported $[6,11,14]$. Forty percent reported a sexual debut in the age group 14-17, earlier than a reported average age of 18.7 years [7]. Sexual activity was also more prevalent than previously reported, with $68 \%$ sexually experienced with a male, and sexual involvement with females in $50 \%$. No involvement with a male was reported for $24 \%$ of our subjects, compared to $37 \%$ from a report of older women [14]. It should be noted that the age range in this study extended to younger individuals than most previous studies.

The broad range of pubertal milestones and menarche was comparable to that in the general population, in contrast to a previous report of early pubertal onset [10]. Most patients reported here saw the same endocrinologist most of their lives, indicated a reasonable understanding of their condition, and had reasonable compliance in contrast to reports from developing countries indicating inconsistent care and poor knowledge of the condition and treatment requirements [15].

Although detailed surgical information is not available for most of this study group and was inadequate for assessment, genital sensation was reported as good by $77 \%$ of patients. Thus, most patients reported positive sensations during clitoral stimulation and the ability to achieve orgasm, compared with the findings in the literature of diminished clitoral sensitivity being worse in those with severe CYP21A2 mutations. Neither genetic analyses of mutations nor Prader stages at presentation were available in our patients, so severity of the enzyme defect cannot be assessed. A relationship has been reported between CYP21A2 genotype/severity of CAH/ prenatal androgen exposure and psychological effects, including problems with gender identity and more surgical complications [1, 2, 5, 8, 12, 16, 17]. The former is evidenced by signs of gender and sexual orientation, with more severely affected women having an increased percentage of bisexual or homosexual orientation. Regarding surgical outcome, the higher the level of confluence of the urethra and vagina, the poorer the cosmetic outcome [12]. Since feminizing surgery and psychological adjustment is not satisfactory for those with the most severe virilization, it has been suggested that the dictum that all patients with a 46,XX karyotype be raised as females should be challenged and a male assignment should be considered those most virilized [18].

Other outcome data associated with severity of CAH include less formal education, more with disability pensions, sick leave, lower marriage rates, and fewer having children [19]. Previous reports have indicated poor academic performance and generally poor communication, which led to social limitations [20]. The current study found financial status and a spectrum of education similar to that of the general population, with no suggestion that their education level relates to the severity of their condition.

The limitations of this study include the lack of a control group; unavailability of complete medical records; and the lack of information about severity of virilization at birth, CYP21A2 genotype, and specific type of surgical procedures performed. Also, it must be noted that responses, particularly regarding sexual experiences, are those at the time of the questionnaire, and that broader experiences in the future may impact future QoL. When the number of undeliverable mailed questionnaires is subtracted from the total, the response rate was low $(27 / 64,42 \%)$ likely due the length of the questionnaire, the lack of on-going contact of the authors with the patients, and the impersonal way (mail) the questionnaire had to be delivered. While the generalizability of our findings is limited by the small sample size, given the scarcity of outcome data on these important aspects of psychosexual health in females with $\mathrm{CAH}$, the study contributes some valuable data.

\section{Conclusion}

This report, which includes a majority of patients who had moderately virilized external genitalia at birth, suggests that outcome of CAH can be very good, with a relationship between both quality of care and positive social support and young adult QoL. Future outcome studies may produce more positive results, with refined surgical techniques, positive psychosocial support, and shifts in cultural acceptance having a positive impact $[18,19]$. 


\section{Additional file}

Additional file 1: Questionnaire. (DOC $52 \mathrm{~kb}$ )

\section{Competing interests}

The authors declare that they have no competing interests.

\section{Authors' contributions}

This manuscript has been the joint venture of several authors as follows: MK tablulated the data, analyzed it and prepared it for statistical analyses and wrote the first draft of the manuscript. JF was instrumental in reviewing medical records, recruiting study subjects and all aspects of data evaluation and manuscript preparation, RR provided names and contact information of potential study patients, wrote letters to recruit them and was involved in the manuscript preparation. $\mathrm{CH}$ major contribution was in creating the study questionnaire after reviewing existing questionnaires in the public domain. DM did the statistical analyses and was involved in manuscript preparation. $\mathrm{PL}$ was involved in all aspects of this study. All authors read and approved the final manuscript.

\section{Author details}

${ }^{1}$ Department of Pediatric Endocrinology, Emory University School of Medicine, Atlanta, GA, USA. ${ }^{2}$ Section of Pediatric Endocrinology, Riley Hospital for Children, Indianapolis, IN, USA. 'Division of Pediatric Urology, Riley Hospital for Children, Indianapolis, IN, USA. ${ }^{4}$ Department of Pediatrics, Georgia Regents University, College of Medicine, Augusta, GA, USA. ${ }^{5}$ Public Health Sciences, Penn State Hershey Medical Center, Hershey, PA, USA. ${ }^{6}$ Department of Pediatrics, Penn State College of Medicine, 500 University Drive, Hershey, PA 17033-0850, USA.

Received: 21 April 2015 Accepted: 21 September 2015

Published online: 15 October 2015

\section{References}

1. Nordenstrom A, Frisen L, Falhammar H, Filipsson H, Holmdahl G, Janson PO, et al. Sexual function and surgical outcome in women with congenital adrenal hyperplasia due to cyp21a2 deficiency: clinical perspective and the patients' perception. J Clin Endocrinol Metab. 2010;95:3633-40.

2. Wisniewski AB, Migeon CJ, Malouf MA, Gearhart JP. Psychosexual outcome in women affected by congenital adrenal hyperplasia due to 21-hydroxylase deficiency. J Urol. 2004;171:2497-501.

3. Nordenstrom A. Adult women with 21-hydroxylase deficient congenital adrenal hyperplasia, surgical and psychological aspects. Curr Opin Pediatr. 2011;23:436-42.

4. Krege S, Walz KH, Hauffa BP, Korner I, Rubben H. Long-term follow-up of female patients with congenital adrenal hyperplasia from 21-hydroxylase deficiency, with special emphasis on the results of vaginoplasty. BJU Int. 2000;86:253-8. discussion 258-259.

5. Stikkelbroeck NM, Beerendonk CC, Willemsen WN, Schreuders-Bais CA, Feitz WF, Rieu PN, et al. The long term outcome of feminizing genital surgery for congenital adrenal hyperplasia: Anatomical, functional and cosmetic outcomes, psychosexual development, and satisfaction in adult female patients. J Pediatr Adolesc Gynecol. 2003;16:289-96.

6. Dessens AB, Slijper FM, Drop SL. Gender dysphoria and gender change in chromosomal females with congenital adrenal hyperplasia. Arch Sex Behav. 2005;34:389-97.

7. Frisen L, Nordenstrom A, Falhammar H, Filipsson H, Holmdahl G, Janson PO, et al. Gender role behavior, sexuality, and psychosocial adaptation in women with congenital adrenal hyperplasia due to cyp21a2 deficiency. J Clin Endocrinol Metab. 2009;94:3432-9.

8. Hines M, Brook C, Conway GS. Androgen and psychosexual development: core gender identity, sexual orientation and recalled childhood gender role behavior in women and men with congenital adrenal hyperplasia (CAH). J Sex Res. 2004:41:75-81.

9. Gupta DK, Shilpa S, Amini AC, Gupta M, Aggarwal G, Deepika G, et al. Congenital adrenal hyperplasia: long-term evaluation of feminizing genitoplasty and psychosocial aspects. Pediatr Surg Int. 2006;22:905-9.

10. Johannsen TH, Ripa CP, Mortensen EL, Main KM. Quality of life in 70 women with disorders of sex development. Eur J Endocrinol. 2006;155:877-85.
11. Jurgensen M, Kleinemeier E, Lux A, Steensma TD, Cohen-Kettenis PT, Hiort O, et al. Psychosexual development in adolescents and adults with disorders of sex development-results from the german clinical evaluation study. J Sex Med. 2013;10:2703-14.

12. Van der Zwan YG, Janssen EH, Callens N, Wolffenbuttel KP, Cohen-Kettenis PT, van den Berg M, et al. Severity of virilization is associated with cosmetic appearance and sexual function in women with congenital adrenal hyperplasia: a cross-sectional study. J Sex Med. 2013;10:866-75.

13. Lesma A, Bocciardi A, Corti S, Chiumello G, Rigatti P, Montorsi F. Sexual function in adult life following Passerini-Glazel feminizing genitoplasty in patients with congenital adrenal hyperplasia. J Urol. 2014;191(1):206-11. doi:10.1016/j.juro.2013.07.097.

14. Gastaud F, Bouvattier C, Duranteau L, Brauner R, Thibaud E, Kutten F, et al. Impaired sexual and reproductive outcomes in women with classical forms of congenital adrenal hyperplasia. J Clin Endocrinol Metab. 2007;92:1391-6.

15. Zainuddin AA, Grover SR, Shamsuddin K, Mahdy ZA. Research on quality of life in female patients with congenital adrenal hyperplasia and issues in developing nations. J Pediatr Adolesc Gynecol. 2013;26:296-304.

16. Meyer-Bahlburg HF, Dolezal C, Zucker KJ, Kessler SJ, Schober JM, New MI. The recalled childhood gender questionnaire-revised: a psychometric analysis in a sample of women with congenital adrenal hyperplasia. J Sex Res. 2006:43:364-7.

17. Meyer-Bahlburg HF, Dolezal C, Baker SW, New MI. Sexual orientation in women with classical or non-classical congenital adrenal hyperplasia as a function of degree of prenatal androgen excess. Arch Sex Behav. 2008;37:85-99.

18. Houk CP, Lee PA. Approach to assigning gender in $46, X X$ congenital adrenal hyperplasia with male external genitalia: Replacing dogmatism with pragmatism. J Clin Endocrinol Metab. 2010;95(10):4501-8.

19. Strandqvist A, Falhammar H, Lichtenstein P, Hirschberg AL, Wedell A, Norrby C, et al. Suboptimal psychosocial outcomes in patients with congenital adrenal hyperplasia: epidemiological studies in a nonbiased national cohort in Sweden. J Clin Endocrinol Metab. 2014;99:1425-32.

20. Zhu D, Hu L, Wan X, Li H, You Q, Gao L, et al. Quality of life evaluation in juveniles with disorders of sexual development. Pediatr Surg Int. 2012;28:1119-23.

\section{Submit your next manuscript to BioMed Central and take full advantage of:}

- Convenient online submission

- Thorough peer review

- No space constraints or color figure charges

- Immediate publication on acceptance

- Inclusion in PubMed, CAS, Scopus and Google Scholar

- Research which is freely available for redistribution 